\title{
Atribuições Dadas à Matemática e Ansiedade ante a Matemática: o relato de alguns estudantes do ensino fundamental
}

\author{
Attributions Given to Mathematics, and the Math Anxiety: The Report of \\ Some Elementary School Students
}

Alessandra Campanini Mendes ${ }^{*}$
João dos Santos Carmo

\begin{abstract}
Resumo
O presente estudo objetivou identificar, em relato de alunos, atribuições dadas à Matemática, bem como graus de ansiedade ante a Matemática. No Estudo 1 foi aplicada a técnica brainstorming que consistiu em escrever, em uma folha de papel, tudo o que ocorre diante da palavra matemática. Participaram 57 estudantes do Ensino Fundamental, 28 do $2^{\circ}$ ano e 29 do $6^{\circ}$ ano. Os alunos do $6^{\circ}$ ano atribuíram mais características negativas à Matemática do que os do $2^{\circ}$ ano. No Estudo 2, aplicou-se uma escala de ansiedade à Matemática a quatro crianças do $6^{\circ}$ ano, aleatoriamente selecionadas do estudo 1 . Observou-se que as situações que os alunos indicaram alta ou extrema ansiedade foram aquelas em que poderiam falhar e sofrer alguma punição. São discutidos o aumento das atribuições negativas com o passar dos anos e a necessidade de metodologias que previnam a aversão à Matemática.
\end{abstract}

Palavras-chave: Atribuições. Matemática. Ansiedade. Aprendizagem. Ensino Fundamental.

\begin{abstract}
This study aimed to identify attributions to mathematics and degrees of anxiety related to mathematics. Study 1 applied the brainstorming technique, which consisted in writing, on a sheet of paper, everything that occurs before the word "Mathematics". Fifty seven elementary school students participated, 28 of $2^{\text {nd }}$ grade and 29 of $6^{\text {th }}$ grade. Sixth grade students attributed more negative characteristics to mathematics than those of $2^{\text {nd }}$ grade. Study 2 applied a math anxiety scale to four children in $6^{\text {th }}$ grade, randomly selected from study 1 . It was observed that situations in which students showed high or extreme anxiety were those in which they were exposed to conditions such as exams, schoolwork, and going to the blackboard. Data are discussed in terms of the increase in negative attributions over the years and the need for methodologies that prevent the aversion to mathematics.
\end{abstract}

\footnotetext{
* Mestre em Psicologia pela Universidade Federal de São Carlos (UFSCar). Doutoranda em Psicologia pela UFSCar, com bolsa CAPES, São Carlos, São Paulo, Brasil. Endereço para correspondência: Programa de PósGraduação em Psicologia, Universidade Federal de São Carlos, Rodovia Washington Luis, Km 235, Bairro Monjolinho, CEP 13565-905, São Carlos/SP, Brasil. E-mail: alessandra.campanini@gmail.com.

** Doutor em Educação pela Universidade Federal de São Carlos (UFSCar). Professor Adjunto do Departamento de Psicologia da UFSCar e do Programa de Pós-Graduação em Psicologia da UFSCar, São Carlos, São Paulo, Brasil. Pesquisador do Instituto Nacional de Ciência e Tecnologia sobre Comportamento, Cognição e Ensino (INCT-ECCE), São Carlos, São Paulo, Brasil. Endereço para correspondência: Departamento de Psicologia, Universidade Federal de São Carlos, Rodovia Washington Luis, Km 235, Bairro Monjolinho, CEP 13565-905, São Carlos/SP, Brasil. E-mail: jcarmo@ufscar.br.
} 
Keywords: Attributions. Mathematics. Anxiety. Learning. Elementary school children..

\section{Introdução}

A Matemática geralmente desperta sentimentos contraditórios nos estudantes (CORREA; MACLEAN, 1999). Se por um lado alguns alunos reconhecem que a Matemática é importante em suas vidas, por outro há uma insatisfação generalizada diante dos resultados negativos obtidos, em forma de notas baixas, dificuldades de compreensão dos conceitos e de resolução adequada dos problemas.

De acordo com Fragoso (2001), as dificuldades na aprendizagem da Matemática podem não estar relacionadas à complexidade da disciplina em si, mas a fatores emocionais oriundos de processos pedagógicos mal direcionados em sala de aula. Corroborando o que diz Fragoso (2001), Carmo (2010) sugere que experiências negativas em sala de aula podem gerar nos estudantes, sentimentos de aversão à Matemática, expectativas negativas e concepções inadequadas sobre a disciplina.

Alunos no contexto da aprendizagem da Matemática escolar relatam sensações como medo e aversão, bem como apresentam reações de fuga e esquiva diante de qualquer situação ligada ao estudo dessa disciplina. Ao conjunto de reações emocionais negativas que certos alunos apresentam durante a aprendizagem da Matemática, denominou-se de ansiedade ante a Matemática (GEARY, 1996; MENDES; CARMO, 2011; TOBIAS, 1978). A ansiedade à Matemática é mais apropriadamente descrita como padrões de reações comportamentais (fuga e esquiva), cognitivas (regras e autorregras depreciativas) e fisiológicas desagradáveis diante de situações que envolvem a aplicação de algum conhecimento matemático (CARMO, 2011). A intensidade e a alta frequência com que essas reações ocorrem em alguns indivíduos são relatadas por estes como uma sensação de total paralisia e desamparo frente à Matemática, levando-os frequentemente a desistir da escola ou a escolher profissões e cursos superiores que, supostamente, não exigiriam conhecimentos matemáticos (TOBIAS, 1978). Desta forma, é possível que ansiedade à Matemática e dificuldades de aprendizagem da Matemática estejam relacionadas e as raízes desses dois fenômenos podem estar relacionadas com as experiências vividas, principalmente, em sala de aula.

As dificuldades de aprendizagem da Matemática frequentemente são atribuídas ao aluno, mas também poderiam ser vistas como dificuldade de ensino da Matemática por parte do professor, tanto pelo domínio da dimensão conteúdo, como também pelo conhecimento de 
como ocorre a aprendizagem, a fim de que as situações didáticas propostas em sala de aula não gerem os comportamentos de fuga e esquiva tão típicos nas aulas de Matemática.

Almeida e Alvez (2002) identificaram diferentes fatores determinantes das dificuldades de aprendizagem: fatores relacionados à saúde geral do estudante; fatores de ordem sensorial; fatores neurológicos; fatores emocionais. Porém, fundamentalmente, a experiência travada diretamente com a disciplina, a metodologia de ensino e os padrões de interação professor-aluno, são determinantes na aversão e, portanto, nas dificuldades apresentadas pelos estudantes. Por outro lado, não se pode estabelecer um processo de culpa sobre o professor, pois tal postura reduziria uma questão complexa unicamente a aspectos relacionados à ação pedagógica em sala de aula (CARRAHER; CARRAHER; SCHLIEMANN, 2006).

Um amplo levantamento conduzido por Zunino (1995), com pais, estudantes e professores, revelou que as origens da aversão e das dificuldades relacionadas à Matemática são, em grande medida, culturais. Pais que apresentam dificuldades em Matemática podem, inadvertidamente, tecer comentários inapropriados para ou diante dos filhos. Professores com alguma aversão ou dificuldades em determinados conteúdos podem estabelecer nos alunos certo receio. Além disso, a comunidade verbal frequentemente transmite uma imagem inadequada da Matemática, apresentando-a como algo de difícil apreensão, acessível a poucos, e que exige muito esforço para ser aprendida. Não é raro, ainda hoje, que exercícios de Matemática sejam aplicados a alunos considerados indisciplinados, como forma de punição. Em consonância com os achados de Zunino, outros estudos identificaram as raízes culturais da aversão à Matemática (ASHCRAFT, 2002; FRANKENSTEIN, 1989; GEARY, 1996).

Identificar as concepções dos estudantes acerca da Matemática pode fornecer indícios importantes sobre como as aversões são formadas ao longo da história escolar e o quanto antes forem identificadas, a chance de intervenção é maior. Além disso, podem fornecer informações relevantes sobre metodologias e estratégias pedagógicas inadequadas e que aumentam as chances de fracasso na aprendizagem dessa disciplina. Nesse sentido, alguns estudos buscaram identificar atitudes de estudantes em relação à Matemática, particularmente utilizando escalas padronizadas (BRITO, 1998; SILVA; BRITO; VENDRAMINI, 2002; MENDES; CARMO, 2011).

Uma estratégia alternativa, chamada de brainstorming (NUSSBAUM; NOVAK, 1981; WATTS, 1990) foi utilizada por Carmo, Cunha e Araújo (2007). Essa técnica, de aplicação 
extremamente simples, consiste em apresentar a palavra escrita matemática e solicitar aos participantes que escrevam tudo o que lhes ocorre, de imediato, a respeito daquela palavra. Esses autores aplicaram o brainstorming a seis alunos do $6^{\circ}$ ao $8^{\circ}$ ano de uma escola da rede pública de ensino da cidade de São Carlos/SP, que tipicamente apresentavam dificuldades em Matemática. Como resultado, os autores verificaram que os alunos apresentaram algumas concepções relacionadas à Matemática, tendo prevalecido as atribuições negativas a essa disciplina. Foi possível observar quais opiniões, sensações e concepções os alunos demonstraram sobre a Matemática, uma vez que puderam colocar na folha de papel tudo aquilo que pensavam a respeito.

O potencial da técnica brainstorming para o acesso das atribuições dadas à Matemática pode ser complementado com o uso de escalas padronizadas. No estudo de Mendes e Carmo (2011) os autores utilizaram a Escala de Ansiedade à Matemática (EAM), sendo possível identificar diferentes graus de ansiedade ante a Matemática em estudantes do Ensino Fundamental e Médio, particularmente os casos de extrema ansiedade. Não há, entretanto, estudos que utilizam os dois instrumentos (escala e brainstorming) como complementares. Além disso, o estudo de Carmo et al. (2007) foi aplicado a um número pequeno de estudantes, os quais já apresentavam, previamente, uma história de fracasso em Matemática.

Com base nessas considerações, o presente artigo apresenta dois estudos complementares. O primeiro, baseado em Carmo et al. (2007), utilizou a técnica de brainstorming com o objetivo de identificar as atribuições dadas à Matemática por crianças do $2^{\circ}$ e do $5^{\circ}$ ano do Ensino Fundamental. O segundo utilizou a EAM, a qual foi aplicada a estudantes que participaram do primeiro estudo e que tipicamente apresentaram atribuições negativas à Matemática. A descrição detalhada desses estudos é feita a seguir.

\section{Estudo 1}

O Estudo 1 objetivou replicar os achados de Carmo et al. (2007), por meio da técnica de brainstorming, porém estendendo seus achados a estudantes do $2^{\circ}$ e do $5^{\circ}$ ano do Ensino Fundamental. Adicionalmente, buscou-se identificar se haveria diferenças acentuadas nas atribuições de estudantes iniciantes no estudo da Matemática escolar e estudantes que já estudavam Matemática há mais tempo. Um terceiro objetivo foi o de identificar quais atribuições à Matemática eram mais frequentes e se havia diferenças nas atribuições e frequências de atribuições entre meninos e meninas. 


\subsection{Método}

\subsubsection{Participantes}

Os participantes foram 49 alunos de duas turmas de diferentes escolas da cidade de São Carlos/SP, sendo 28 estudantes do $2^{\circ}$ ano do Ensino Fundamental (14 meninas e 14 meninos), com média de idade de 6,5 anos, e 21 estudantes do $6^{\circ}$ ano do Ensino Fundamental (10 meninas e 11 meninos), com média de idade de 12,5 anos. ${ }^{1}$

\subsection{Procedimento}

A coleta ocorreu na sala de aula de cada turma. Inicialmente foram entregues duas folhas de papel tamanho A4 para cada estudante. Solicitou-se a cada aluno que escrevesse nas folhas a letra $\mathrm{M}$, caso fosse menino, ou a letra $\mathrm{F}$, caso fosse menina. Para que compreendessem a técnica, foram ditadas duas palavras, e solicitado que as anotassem na folha de papel e escrevessem o que pensavam sobre elas. No $2^{\circ}$ ano as palavras utilizadas foram futebol e televisão. No $6^{\circ}$ ano, as palavras foram celular e internet. Essas palavras foram especialmente escolhidas em função de dois critérios: faziam parte do universo vocabular dos alunos; não havia nenhuma correspondência evidente e direta com a palavra matemática. Esse primeiro momento, portanto, serviu para familiarizar os alunos com o brainstorming.

Em seguida, ditou-se a palavra matemática e, para não deixar dúvidas, também foi escrita na lousa. Solicitou-se aos alunos que escrevessem ao redor da palavra tudo o que lembravam quando ouviam a mesma.

\subsubsection{Organização dos dados}

As declarações dos alunos foram divididas em sete categorias: aspectos positivos; aspectos negativos; conteúdo; aspectos metodológicos; aplicabilidade do conteúdo;

\footnotetext{
${ }^{1}$ Havia um aluno na sala com 14 anos de idade e, de acordo com a direção da escola, era um aluno de inclusão, uma vez que está acima da média da idade para esta etapa de ensino.
} 
indefinido; e outros. Considerou-se aspectos positivos aqueles que lembravam algo agradável para os alunos. Aspectos negativos referiam-se a algo desagradável. Em conteúdo foram separadas as concepções que estavam relacionadas ao que era ensinado em Matemática. Aspectos metodológicos representaram as concepções relacionadas à metodologia de ensino utilizada pelo professor durante a aula. $\mathrm{Na}$ aplicabilidade do conteúdo consideramos aquelas declarações a respeito do que o professor fala acerca da utilidade do conteúdo estudado. Indefinido englobava palavras que não foram compreendidas, quando escritas pelos alunos. $\mathrm{E}$ por último, a categoria outros indicava concepções que não estavam relacionadas diretamente à palavra-tema.

\subsubsection{Resultados e discussão}

A Figura 1 apresenta as categorias para o $2^{\circ}$ ano. Não foram apresentadas concepções a respeito de aspectos metodológicos e aplicabilidade do conteúdo por nenhum dos sexos, por isso não foram consideradas na figura. $\mathrm{Na}$ categoria indefinido registrou-se somente uma palavra sem qualquer significado aparente (munetrelis), escrito por uma menina. Em outros apenas uma palavra foi registrada por um menino (caneta).

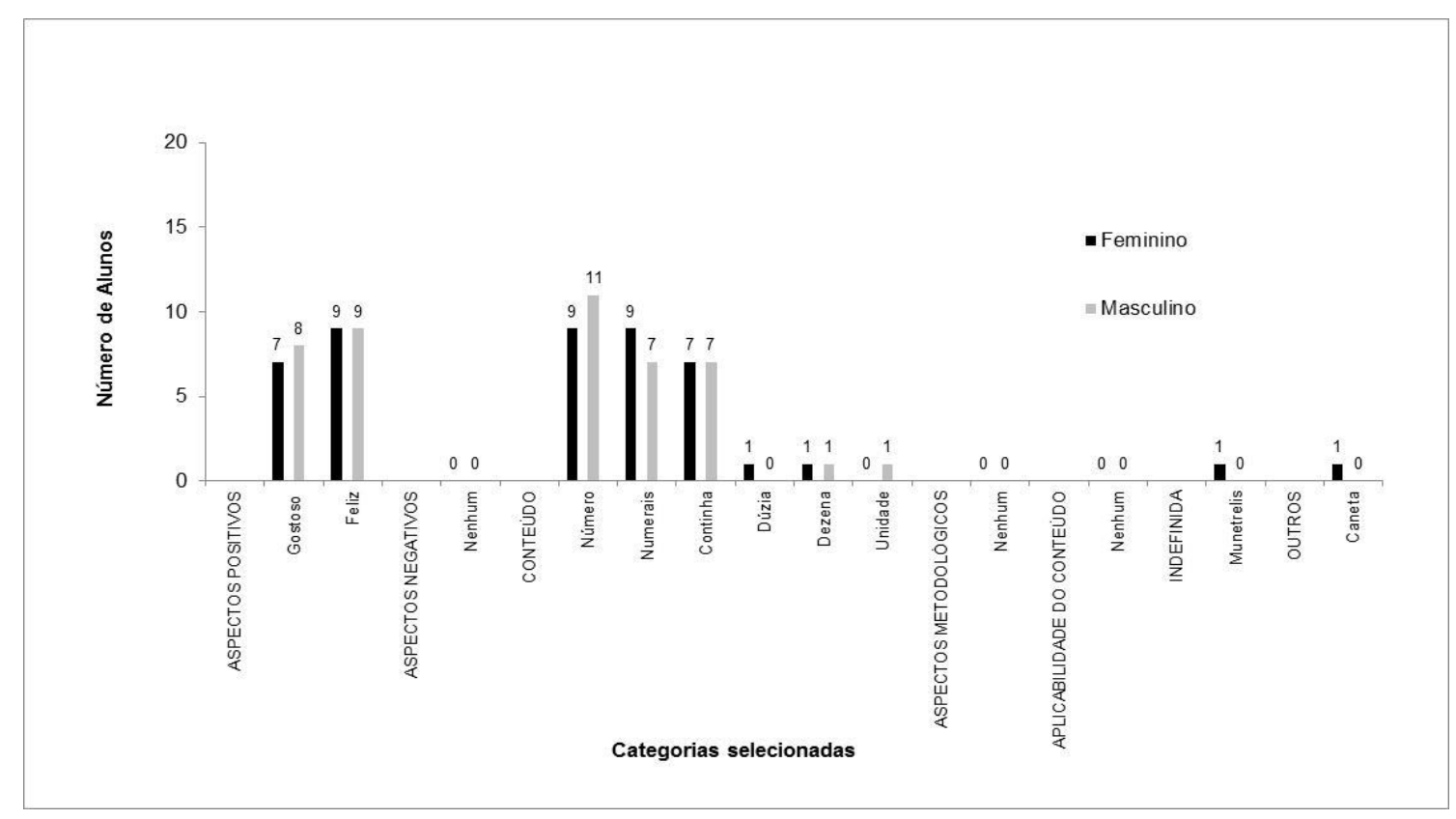

Figura 1- Atribuições dadas à Matemática pelos alunos do $2^{\circ}$ ano, distribuídos por categorias e por sexo Fonte: elaborado pelos autores

De um modo geral, as meninas apresentaram maior número de declarações que os meninos. A categoria mais representativa foi a de conteúdo, tanto para meninos quanto para 
meninas. Não houve nenhuma indicação de atribuições negativas à Matemática, porém foram registradas 33 atribuições positivas. Resumidamente, os dados do $2^{\circ}$ ano apontam para uma ausência de qualquer indício de aversão à Matemática, além de um significativo número de referências a aspectos positivos e a conteúdos.

Para exemplificar as categorias com mais declarações, foram selecionadas duas folhas de respostas dos alunos, com suas respectivas atribuições, conforme a seguir.

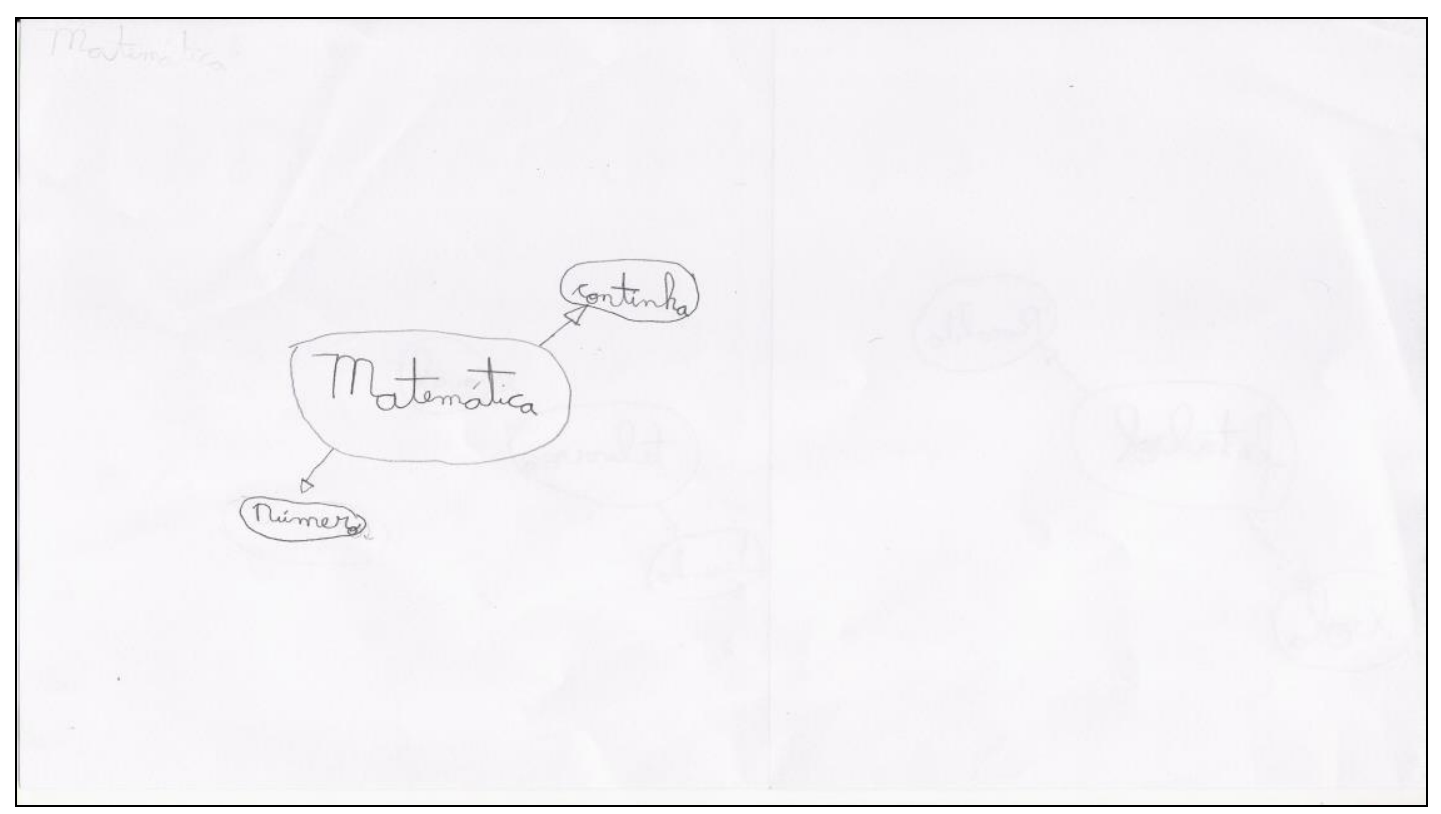

Ilustração 1- Folha de resposta de uma aluna do $2^{\circ}$ ano. Categoria aspectos positivos Fonte: dados da pesquisa

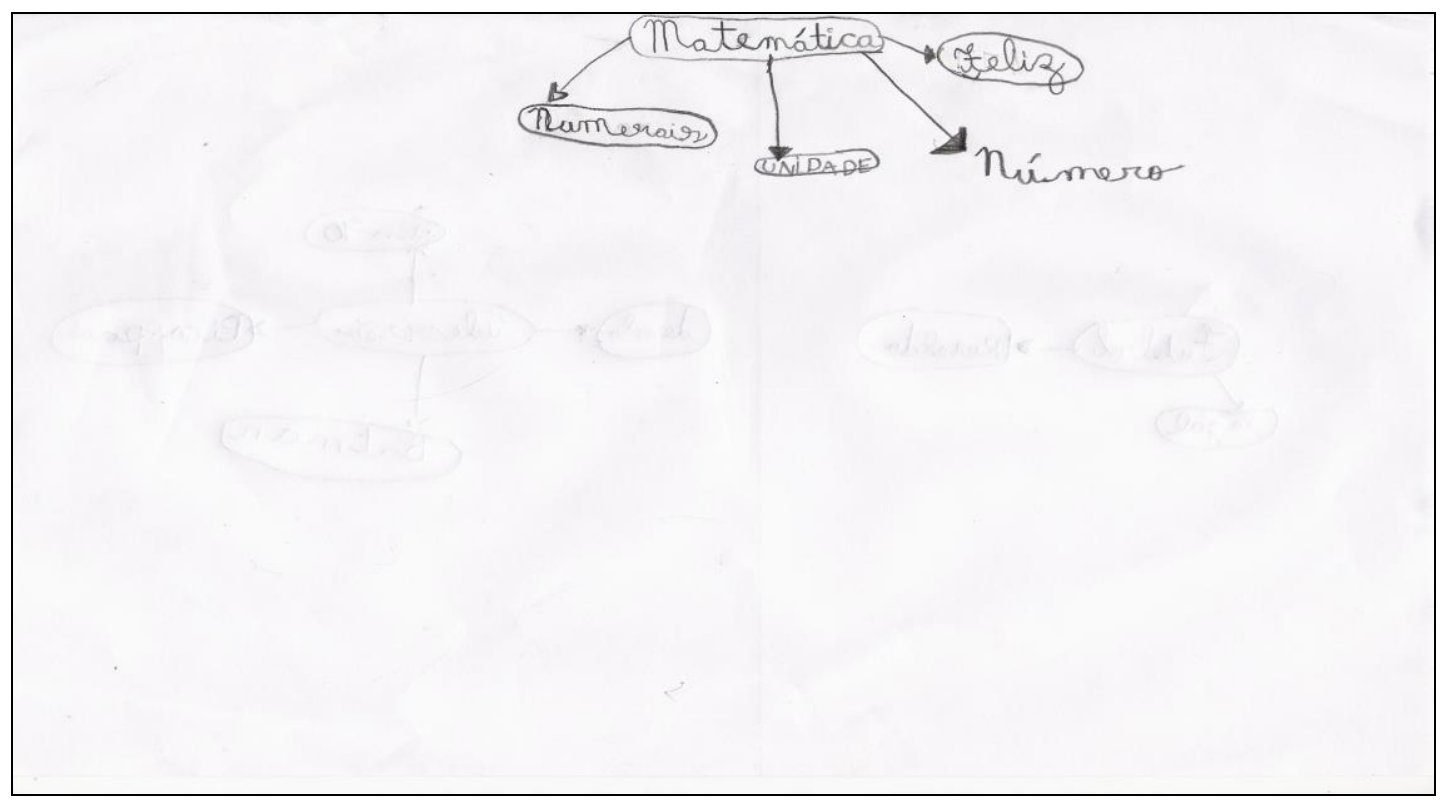

Ilustração 2 - Folha de resposta de um aluno do $2^{\circ}$ ano. Categoria aspectos positivos Fonte: dados da pesquisa 
A Figura 2, a seguir, apresenta as atribuições explicitadas pelos alunos do $6^{\circ}$ ano. Os dados revelam que as concepções apresentadas pelas meninas também aparecem em maior quantidade que as dos meninos. Observando a figura, é possível notar que o número de atribuições à Matemática pelos alunos do $6^{\circ}$ ano é maior que as do $2^{\circ}$ ano, considerando ambos os sexos.

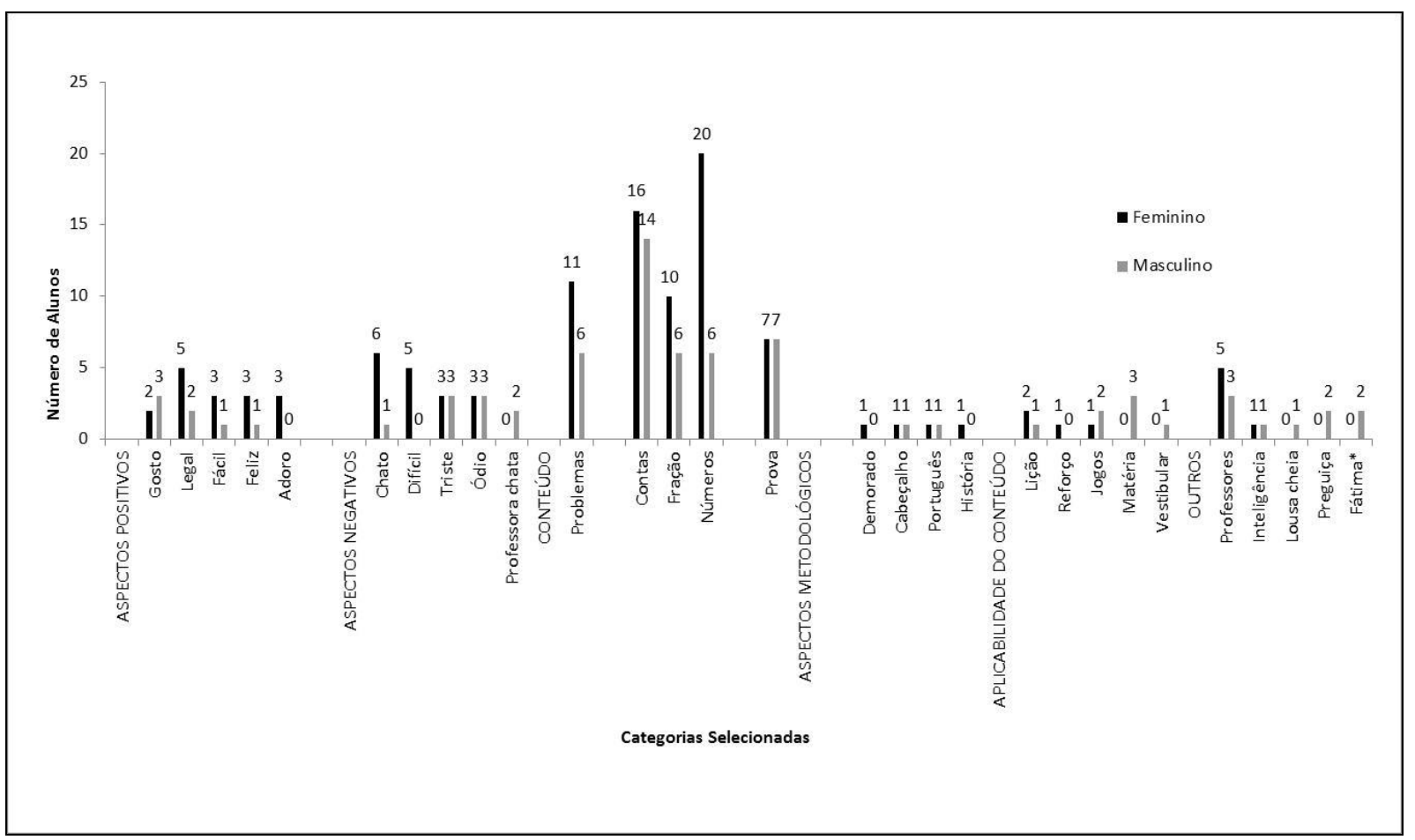

Figura 2 - Atribuições dadas à Matemática pelos alunos do $6^{\circ}$ ano, distribuídos por categorias e por sexo Fonte: elaborado pelos autores

Nota-se que, para o $6^{\circ}$ ano, aparecem muitas atribuições negativas à Matemática, as quais superam em quantidade as atribuições positivas. Tal como no $2^{\circ}$ ano, também há um número significativo de declarações referentes a conteúdo.

Para exemplificar as atribuições mais frequentes, foram selecionadas duas folhas de respostas dos alunos, com suas respectivas opiniões, conforme a seguir. 


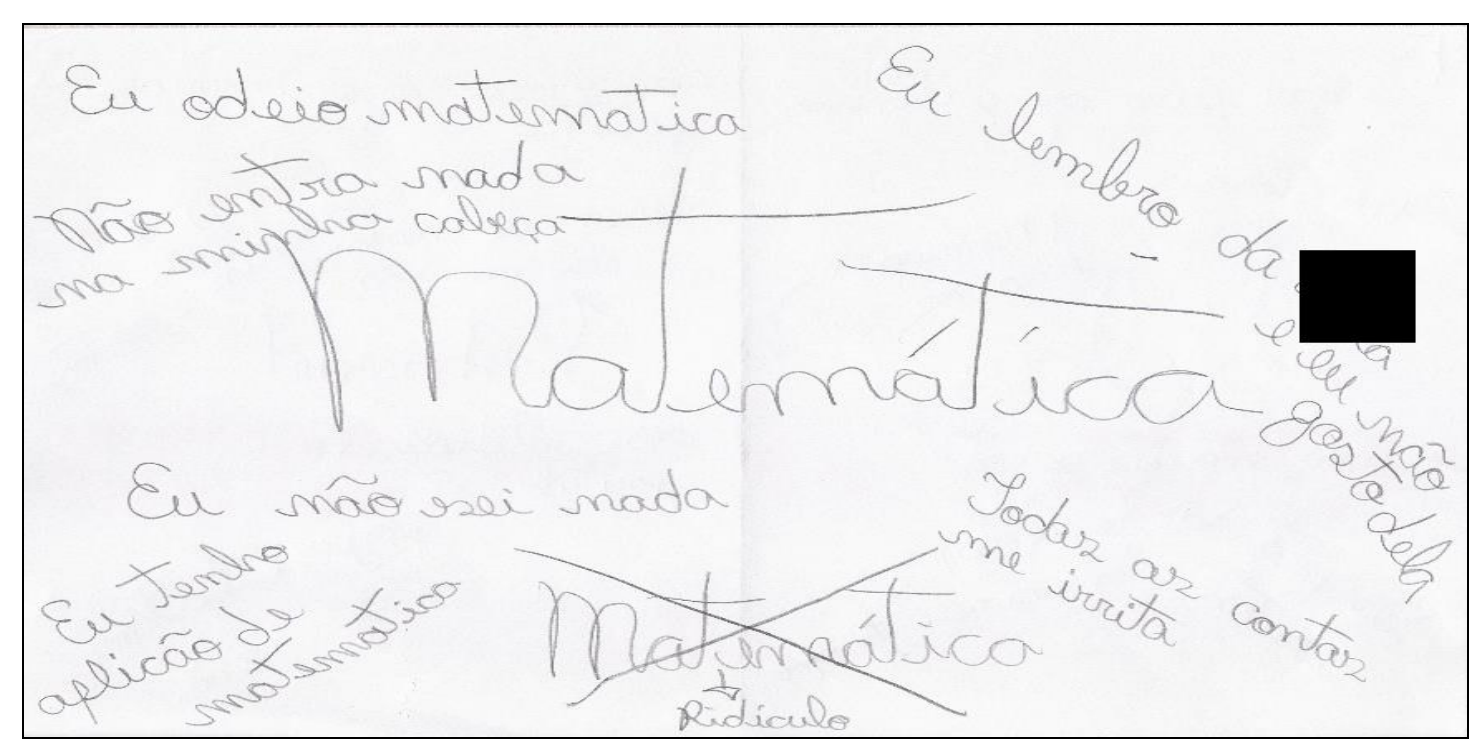

Ilustração 3- Folha de resposta de uma aluna do $6^{\circ}$ ano. Categoria aspectos negativos. O nome da professora ficou ocluso na presente ilustração.

Fonte: dados da pesquisa

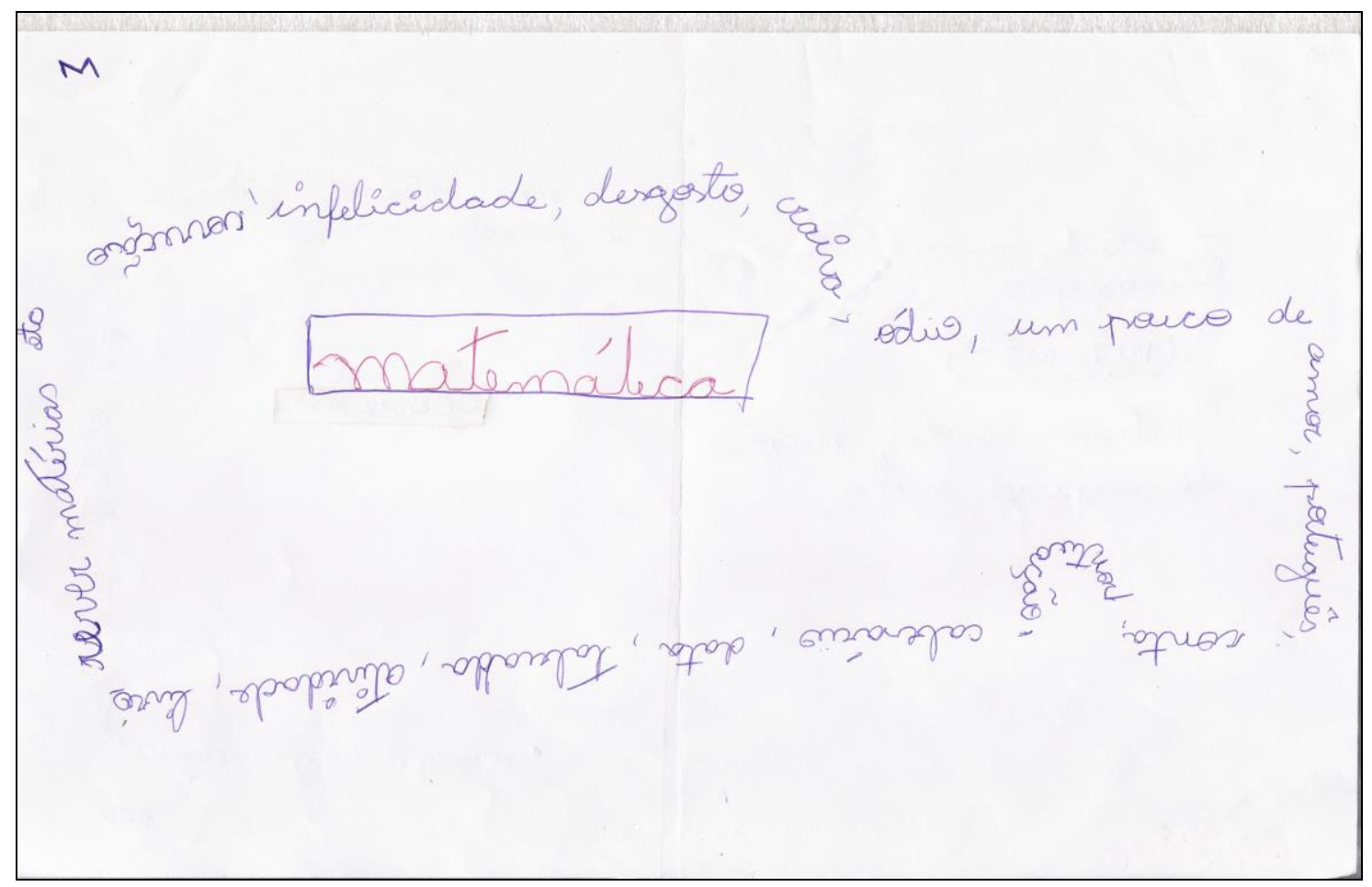

Ilustração 4 - Folha de respostas de um aluno do $6^{\circ}$ ano. Categoria conteúdo Fonte: dados da pesquisa

Com o objetivo de comparar as atribuições dadas por cada sexo, foram comparadas as respostas das meninas das duas séries, apresentadas na Figura 3. 


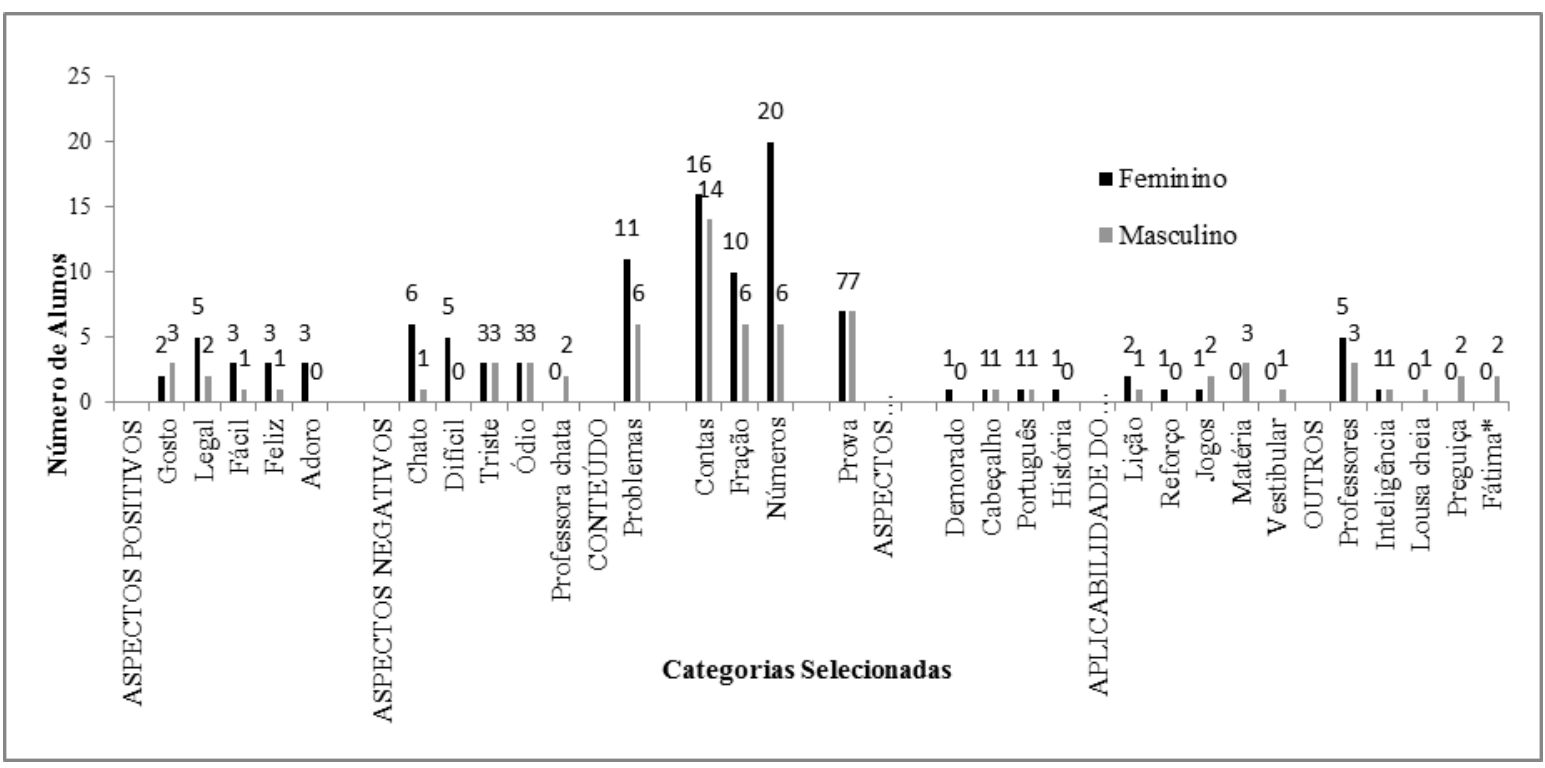

Figura 3 - Comparação entre as atribuições dadas à Matemática pelas alunas do $2^{\circ}$ e $6^{\circ}$ ano Fonte: elaborado pelos autores

A Figura 3 revela que as meninas do $6^{\circ}$ ano apresentaram mais atribuições à Matemática que as do $2^{\circ}$ ano, independentemente da categoria de atribuição. Por outro lado, é nítida a diferença de vocabulário entre as séries, o que possibilitou, inclusive, que as alunas mais velhas usassem termos para se referir negativamente à matemática. As únicas concepções que são expostas em comum por ambas as séries são: "feliz", "numerais" e "números", sendo que duas estão relacionadas ao conteúdo em si, e não a aspectos vivenciais, isto é, à existência de vínculos positivos ou negativos na aprendizagem da Matemática.

Da mesma maneira, foi realizada uma comparação entre as características atribuídas pelos meninos das duas séries, conforme demonstrado na Figura 4.

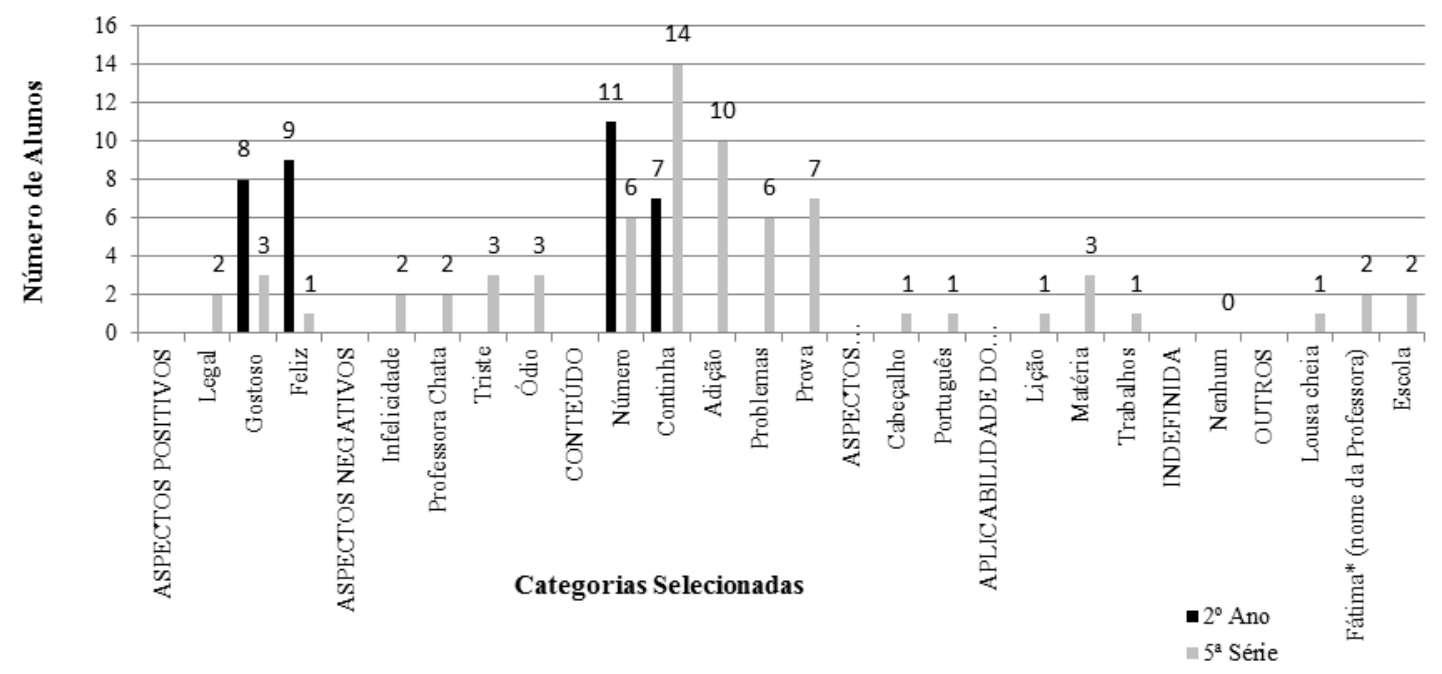

Figura 4 - Comparação entre as atribuições dadas à Matemática pelos alunos do $2^{\circ}$ e $6^{\circ}$ ano Fonte: elaborado pelos autores 
Conforme pode ser observado, das características apresentadas no gráfico, as citadas pelos alunos das duas turmas foram "gostoso", "feliz", "números" e "contas". Estas também foram as únicas apresentadas pelos alunos do $2^{\circ}$ ano, relevantes neste gráfico. As demais foram apresentadas apenas pelos alunos do $6^{\circ}$ ano.

Os dados indicam que os alunos do $6^{\circ}$ ano foram os que relataram um maior número de atribuições à Matemática, principalmente no que tange aos aspectos negativos. Isso mostrou que, na presente amostra, os alunos com mais idade, quando comparados aos de menos, foram os que demonstraram características negativas à disciplina. Comparando os resultados da técnica utilizada no presente trabalho com o estudo de Carmo et al. (2007), podemos afirmar que houve semelhanças no que diz respeito às atribuições dos alunos, já que nas duas pesquisas, os aspectos negativos foram o que apareceram com maior frequência.

Nitidamente, os dados evidenciam uma diferença marcante em relação à presença de aversão em relação à Matemática. Enquanto os estudantes do $2^{\circ}$ ano não expressam qualquer aversão relacionada a essa disciplina, no $6^{\circ}$ ano há uma quantidade significativa de atribuições negativas. Em um estudo conduzido por Mandarino (2004), no qual a autora fez um extenso levantamento acerca das variações no gostar da Matemática em estudantes do $2^{\circ}$ ao $5^{\circ}$ ano, de escolas públicas e particulares, ficou evidenciado que a aversão à Matemática nas primeiras séries é quase que totalmente inexistente. Esses dados são corroborados em nosso estudo, relativo às declarações dadas por nossa amostra do $2^{\circ}$ ano. Além disso, o estudo de Correa e MacLean (1999), embora indique uma flutuação ao longo das séries na atribuição de Matemática como sendo uma disciplina difícil, é nítido que a atribuição de dificuldade tende a um crescimento com o passar dos anos escolares.

O presente estudo, portanto, destaca que a aversão à Matemática, e, por conseguinte, possíveis dificuldades em seu aprendizado, está relacionada à série e, possivelmente, aos aspectos culturais e pedagógicos indicados na introdução deste relato. Em que medida seria possível identificar alguma relação entre atribuições negativas à Matemática e a presença de ansiedade no aprendizado dessa disciplina? O estudo 2, relatado a seguir, buscou elementos para uma resposta a essa pergunta.

\section{Estudo 2}


Uma vez verificado, por meio do brainstorming, que as concepções negativas apareceram com alta frequência nas atribuições dadas pelos alunos do $6^{\circ}$ ano, buscou-se identificar se havia alguma relação direta entre atribuições negativas à Matemática e grau elevado de ansiedade relacionada à essa disciplina.

O instrumento utilizado foi a Escala de Ansiedade à Matemática (EAM), elaborada em sua primeira versão por Carmo e Figueiredo (2005) e aperfeiçoada por Carmo em $2008^{2}$. Em estudo conduzido com 477 estudantes do Ensino Fundamental e Médio, essa escala mostrouse eficaz na identificação de graus diferenciados de ansiedade à matemática (CARMO; FIGUEIREDO; NOGUEIRA; CUNHA; ARAÚJO; FERRANTI, 2008). A EAM também mostrou-se bastante útil na identificação de graus extremos de ansiedade à Matemática (MENDES; CARMO, 2011). As propriedades psicométricas da escala foram estabelecidas em 2012 a partir de uma amostra de 1106 estudantes, sendo 770 do Ensino Fundamental e 336 do Ensino Médio (MENDES, 2012).

\subsection{Método}

\subsubsection{Participantes}

Foram selecionados quatro estudantes do $6^{\circ}$ ano, participantes do primeiro estudo, dos quais dois eram do sexo feminino (P1 e P2) e dois, do sexo masculino (P3 e P4), todos com 12 anos de idade.

\subsubsection{Material}

A Escala de Ansiedade à Matemática (EAM), do tipo Likert, contém 25 situações do cotidiano escolar, relacionadas à Matemática, sejam em sala de aula ou fora dela. Os participantes foram convidados a escolher apenas uma opção dos cinco graus de ansiedade para cada situação: nenhuma ansiedade; baixa ansiedade; ansiedade moderada; alta ansiedade; extrema ansiedade. Dentre as situações propostas na EAM, estão: "quando escrevo a palavra "matemática"” (3) 3 ; "Um dia antes da aula de matemática" (5); "Durante a aula de matemática, quando devo resolver sozinho um exercício" (8); "Quando o professor de

\footnotetext{
${ }^{2}$ Carmo, J. S. Escala de Ansiedade à Matemática: elementos descritivos e de construção. Universidade Federal de São Carlos. Texto não publicado. 2008.

${ }^{3}$ Os números entre parênteses indicam em que posição a situação aparecia na escala.
} 
matemática me dirige a palavra, fazendo perguntas sobre matemática" (12); "Ao fazer a tarefa de casa de matemática" (14); "Quando os colegas estão falando sobre matemática" (17); "minutos antes da prova de matemática" (20); "No dia da entrega das notas de matemática" $(23)^{4}$ Os 25 itens são distribuídos aleatoriamente, de forma que não há relação entre posição da situação e maior ou menor grau de ansiedade.

\subsubsection{Procedimento}

Os alunos foram chamados individualmente para responder as questões, durante o período da aula, fora da sala de aula, ou seja, no pátio da escola, para que o sigilo das respostas fosse mantido. A folha foi entregue a cada um deles para que assinalassem com a letra $X$ a resposta condizente com o que sentiam diante de cada situação exposta, lembrando que para cada situação era aceita somente uma resposta. Vale lembrar que cada situação foi lida juntamente com os alunos, para que não ficassem com dúvidas de interpretação das situações.

\subsubsection{Resultados e discussão}

Das 25 situações apresentadas, 16 delas foram relacionadas a alta ou extrema ansiedade pelos participantes, incluindo meninos e meninas. Na situação 20 (Um dia antes da prova de matemática), todos os participantes indicaram sentir extrema ansiedade. Situações de alta ou extrema ansiedade também foram indicadas nas situações 10 (Durante a aula de matemática, quando devo mostrar os exercícios ao professor), 16 (Quando em casa não consigo resolver o dever de matemática), 17 (Um dia antes de entregar um dever de casa de matemática que não consegui resolver), 21 (Minutos antes da prova de matemática), 22 (Durante a prova de matemática) e 25 (No dia do resultado final). Na situação 19 (Quando encontro o professor de matemática fora da sala de aula) um menino relatou alta ansiedade e uma menina relatou ansiedade extrema. Nas situações 21 e 22 uma menina declarou extrema ansiedade diante das duas situações e dois meninos declararam alta ansiedade nas mesmas situações. Na situação 24 (No dia da entrega das notas de matemática), dois meninos

\footnotetext{
${ }^{4}$ A escala completa poderá ser fornecida aos interessados, com instruções de aplicação, a partir do contato e autorização de um dos autores.
} 
escolheram extrema ansiedade, e na 25 , dois meninos indicaram extrema e uma menina, alta ansiedade.

Ao comparar os resultados finais entre os sexos, notou-se que as meninas foram as que escolheram em maior número, a opção ansiedade extrema. Elas indicaram extrema ansiedade em 18 das 25 situações e alta ansiedade em 6 delas. Já os meninos apresentaram um número menor de indicação de ansiedade extrema perante as situações expostas. Em 16 situações indicaram extrema ansiedade, e em 8 , alta ansiedade.

Em relação às outras respostas às situações, como nenhuma, baixa ou moderada ansiedade, observamos que as meninas responderam sentir nenhuma ansiedade em 15 delas, baixa ansiedade em 4 delas e ansiedade moderada em 7 delas. Já os meninos indicaram nenhuma ansiedade em 8 das 25 situações, baixa ansiedade e ansiedade moderada em 9 delas.

Percebe-se uma discreta diferença entre as atribuições dadas por meninos e meninas sobre as situações, principalmente no que diz respeito à ansiedade extrema. Pesquisas acerca da relação entre ansiedade à Matemática em homens e mulheres têm revelado que, em geral, mulheres tendem a relatar maior grau de ansiedade do que homens, porém a diferença não é considerada estatisticamente significante (DEVINE; FAWCEYY; SZÜCS; DOWKER, 2012). Os dados da presente pesquisa, apesar da amostra reduzida, corroboram os achados da literatura. Porém, não se pode inferir que essa diferença seja devido a qualquer especificidade de gênero. Em outras palavras, muito provavelmente essa diferença se deve a fatores culturais, tendo em vista que as culturas ocidentais, em diversas situações, são mais tolerantes aos relatos verbais e reações emocionais de medo e ansiedade em meninas do que em meninos. Desse modo, mais declarações e alta ou extrema ansiedade em meninas do que em meninos, tanto no presente estudo quanto na literatura internacional, parece refletir as práticas culturais em relação aos papéis masculinos e femininos (FENNEMA, 2000).

As respostas revelaram que em situações nas quais os alunos são expostos a condições nas quais podem falhar, como uma prova, realização ou exercício na lousa, o grau de ansiedade é extremo. Os dados sugerem que estes alunos, muito provavelmente, foram expostos a situações aversivas, como a retaliação do professor ou dos próprios colegas de turma, ou o fracasso no momento de realizar as tarefas citadas nas situações. Assim, temos a associação de componentes culturais e experiências aversivas de ensino escolar, gerando nos alunos declarações negativas em relação a uma disciplina específica ou a um conjunto específico de ações desenvolvidas pela escola (SIDMAN, 1995). No presente estudo, as 
indicações gerais dadas por Sidman fortalecem a hipótese de que a exposição a contextos inadequados de ensino aumentam as chances de desenvolvimento de repulsa à Matemática.

\section{Considerações finais}

O presente artigo objetivou apresentar os dados de dois estudos interligados acerca das concepções e sentimentos de estudantes em relação à Matemática. Para tanto, a técnica de brainstorming e o uso da Escala de Ansiedade à Matemática foram fundamentais na identificação de fatores cruciais relacionados às concepções dos alunos.

A partir dos dados de ambos os estudos, algumas considerações educacionais derivadas podem ser feitas em relação a classificação, erros dos alunos e forma de avaliação. Carmo (2010) afirma que é comum professores classificarem alunos como bons ou maus, de acordo com seus desempenhos. O mau aluno é, na perspectiva destes professores, aquele que sempre terá um fraco rendimento, refletido nas notas, ao contrário do aluno considerado bom. Isso é um dos fatores decisivos para que o aluno se depare com o fracasso escolar, já que para certos professores, o erro é limitação do aluno. E na maioria das vezes, o erro é apontado a partir da avaliação feita do aluno, pelo professor.

Zabala (1998) afirma que a função social do ensino não objetiva somente promover os mais aptos pelas notas, mas, também, envolve outros quesitos da personalidade do aluno, como os conteúdos capazes de promover as habilidades motoras, de equilíbrio e autonomia pessoal, de relação interpessoal e de inserção social.

Uma opção desta natureza implica uma mudança radical na maneira de conceber a avaliação, posto que o ponto de vista já não é seletivo, já não consiste em ir separando os que não podem superar distintos obstáculos, mas em oferecer a cada um dos meninos e meninas a oportunidade de desenvolver, no maior grau possível, todas suas capacidades. (ZABALA, 1998, p. 197)

Zabala (1998) ainda afirma que o alcance dos objetivos por parte dos alunos é um fator que necessita conhecer os resultados e processos de aprendizagem do aluno. Avaliar significa não apenas atribuir notas, mas verificar em qual etapa de 
aprendizagem a criança se encontra para que o educador possa interferir e ajudar a criança a avançar.

Comparando as afirmações de Carmo (2010) com as de Zabala (1998) é possível afirmar que os dois partem do princípio de que apontar erros é uma tarefa que deve ser repensada pelos professores, pois o fato de um aluno errar nem sempre implica em dificuldades de aprendizagem, mas também, de ensino. $\mathrm{O}$ ato de ensinar não é simples. Ao contrário, requer habilidades, conhecimentos e, principalmente, saber identificar sobre o que o aluno já conhece e o que ele necessita para avançar. Aplicar uma avaliação e apontar possíveis erros com uma nota puramente quantitativa é um equívoco cometido pelo docente, pois essa nota pode significar uma avaliação de seu próprio desempenho como professor.

A presente pesquisa, além de destacar a importância de se investigar os sentimentos dos alunos diante da matemática, também enfatiza a necessidade de se entender as relações entre esses sentimentos e os valores adotados pelo próprio professor em sala de aula. Em um estudo que buscou investigar essa relação, Machado, Frade e Falcão (2010) identificaram que as crenças e valores dos professores em relação à Educação Matemática e à Educação em geral, repercutiam diretamente nos sentimentos e atitudes dos alunos em relação à Matemática. Essas evidências também foram confirmadas em nosso estudo.

Assim, se faz fundamental ao educador e também aos familiares dos alunos, entenderem quais concepções e saberes os alunos já possuem sobre as disciplinas, e neste caso em especial, sobre a Matemática. A intenção desta afirmação não é apontar que todas as dificuldades na disciplina são provenientes da falta de interação entre conteúdo, metodologias de ensino do professor e alunos. Contudo, é fundamental conhecer tais concepções para se construir um diagnóstico do problema, a intervenção e, por consequiência, o real auxílio ao aluno que apresenta ansiedade à Matemática. É de fundamental importância explicar aos alunos que a grande vilã do ensino até agora mencionada é fundamental na construção de saberes e que ela faz parte de nossa vida, e não apenas que preenche lacunas no currículo da escola. Dificuldades existem, mas elas não podem se transformar em barreiras na construção de conhecimento dos alunos.

\section{Referências}

ALMEIDA, R. M.; ALVES, J. B. M. A informática e as dificuldades de aprendizagem: repensando o olhar e a prática do professor no cotidiano da sala de aula. In:FÓRUM DE INFORMÁTICA APLICADA A PESSOAS PORTADORES DE NECESSIDADES ESPECIAIS. CBComp. X.10 2002. 
Anais... Disponível em: <www.cbcomp.univali.Br/anais/pdf/2002/iee005.pdf > Acesso em: 22 mar. 2013

ASHCRAFT, M. H. Math anxiety: personal, educational, and cognitive consequences. Current Directions in Psychological Science, Thousand Oaks, v. 11, n. 5, p.181-185, out. 2002.

BRITO, M. R. F. Adaptação e validação de uma escala de atitudes em relação à matemática. Zetetike, Campinas, v. 6, n. 9, p. 45-63. jan/jun, 1998.

CARMO, J. S. Ansiedade à matemática: identificação, descrição operacional e estratégias de reversão. In: CAPOVILlA, F. C. (Org.). Transtornos de aprendizagem: progressos em avaliação e intervenção preventiva e remediativa. São Paulo: Memnon, 2011 p. 249-255.

CARMO, J. S. Produção de erros no ensino e na aprendizagem: implicações para a interação professor-aluno. In: MIZUKAMI, M. G. N.; REALI, A. M. M. R. (Org.). Aprendizagem profissional da docência: saberes, contextos e práticas. São Carlos, SP: EDUFSCar/INEP/COMPED, 2010. p. 211-227.

CARMO, J. S. FIGUEIREDO, R. M. E.; NOGUEIRA, M. F.; CUNHA, L. O.; ARAÚJO, P. V. S.; FERRANTI, M. C. Diferentes intensidades de ansiedade relatadas por estudantes do Ensino Fundamental II, em situações típicas de estudo da Matemática. In: SILVA, W. C. M. P. (Org.). Sobre Comportamento e Cognição: reflexões epistemológicas e conceituais, considerações metodológicas, relatos de pesquisa. SantoAndré, SP: ESETec, 2008. p. 213-221.

CARMO, J. S.; CUNHA, L. O.; ARAÚJO, P. V. S. Atribuições dadas à matemática por alunos do Ensino Fundamental com dificuldades em matemática: um estudo preliminar. In: V ENCONTRO PARAENSE DE EDUCAÇÃO MATEMÁTICA - EPAEM, 5. 2007. Pará. Anais do V EPAEM. Pará: EdUEPA, 2007. p. 328-335.

CARMO, J. S.; FIGUEIREDO, R. M. E.. Aprendizagem, emoção e ansiedade à matemática: indícios e vestígios de histórias de punição e fracasso no ensino da matemática. Trilhas - revista do Centro de Ciências Humanas e Educação, Belém. v. 7, n. 15, p. 85-93, jan/dez. 2005.

CARRAHER, T. N.; CARRAHER, D.; SCHLIEMANN, A. L. D. Na vida dez, na escola zero. 14 ed. São Paulo: Cortez, 2006.

CORREA, J.; MACLEAN, M. Era uma vez...um vilão chamado matemática: um estudo intercultural da dificuldade atribuída à matemática. Psicologia Reflexão \& Crítica, Porto Alegre,v. 12, n. 001, p. 1-19, jan/jun. 1999.

DEVINE, A.; FAWCETT, K.; SZÜCS, D.; DOWKER, N. Gender differences in mathematics anxiety and the relation to mathematics performance while controlling for test anxiety. Behavioral and Brain Functions, Londres, v. 8, n. 33, p. 2-9. jul. 2012.

FENNEMA, E. Gender and mathematics: What is known and what do I wish was known? Conferência apresentada no FIFTH ANNUAL FORUM OF THE NATIONAL INSTITUTE FOR SCIENCE EDUCATION, 50 ${ }^{\text {th }}$, 2000, Detroit, Michigan. Proceedins... Detroit, Michigan, p. 22-23, mai. 2000.

FRAGOSO, W. C. O medo da matemática. Revista Educação, Santa Maria, v. 26, n. 02, p. 95-109, 2001.

FRANKENSTEIN, M. Relearning mathematics: a different third r-radical math(s). Vol 1. London: Free Association Books, 1989. 
GEARY, D. C. Children's mathematical development: research and practical applications. Washington, DC: American Psychological Association, 1996.

MACHADO, M. C.; FRADE, C.; FALCÃO, J. T. R. Influência de aspectos afetivos na relação entre professor e alunos em sala de aula de matemática. BOLEMA, Rio Claro (SP), v. 23, n. 36, p. 683713, ago. 2010.

MANDARINO, M. C. F. A escola "desfaz" o gosto pela matemática? In: ENCONTRO NACIONAL DE EDUCAÇÃO MATEMÁTICA, 7. 2004,Recife, PE. Anais... Recife, PE.: Sociedade Brasileira de Educação Matemática, 2004. p. 01-14. Disponível em:

<http://www.sbem.com.br/files/viii/pdf/01/2CC43277748715.pdf>Acesso em: 15 mar. 2013.

MENDES, A. C. Identificação de graus de ansiedade à matemática em estudantes do ensino fundamental e médio: contribuições à validação de uma escala de ansiedade à matemática. 2012. 45f. Dissertação (Mestrado em Psicologia), Centro de Educação e Ciências Humanas Universidade Federal de São Carlos, SP. 2012.

MENDES, A. C.; CARMO, J. S. Estudantes com grau extremo de ansiedade à matemática: identificação de casos e implicações educacionais. Psicologia da Educação, São Paulo, n. 33, p. 119133. 2011.

NUSSBAUM, J.; NOVAK, J. Brainstorming in the classroom to invent a model: a case study. School Science Review, Hertfordshire, v. 62, n. 221, p.771-778. 981.

SIDMAN, M. Coerção e suas implicações. Maria Amália Andery (Trad.). Campinas, SP: Editorial Psy, 1995. (texto originalmente publicado em 1989).

SILVA, C. B.; BRITO, M. R. F.; VENDRAMINI, C. M. M. Atitudes em relação à estatística e à matemática. Psico-USF, Itatiba, v. 7, n. 2, p.89-100. jul/dez. 2002

TOBIAS, S. Overcoming math anxiety. New York: Norton, 1978.

ZABALA, A. A avaliação. In: ZABALA, (Ed.). A prática educativa: como ensinar. São Paulo: ArtMed, 1998. 224 p.

ZUNINO, D. L. A matemática na escola: aqui e agora. Juan Acuna Llorens (Trad.). 2. ed. Porto Alegre: Artes Médicas, 1995, $191 \mathrm{p}$.

WATTS, M. De mapas de conceitos a sinalizadores de currículo. Caderno Brasileiro de Ensino de Física, Florianópolis, v. 7, n. 1, p. 7-20, abr. 1990. 